УДК 338.47

\section{JEL 018}

DOI 10.31375/2226-1915-2021-2-38-64

«ДОСТАВКА ОСТАННЬОЇ МИЛІ»

В РАМКАХ МІСЬКОГО РОЗПОДІЛУ І УПРАВЛІННЯ ЛАНЦЮГАМИ

ПОСТАВОК: ОГЛЯД ПЕРЕДОВОГО ДОСВІДУ І КОНЦЕПТУАЛЬНОЇ ОСНОВИ

Марія Арістея Бакогіанні $\mathrm{PhD}$

\section{Джорж Маліндретос}

$\mathrm{PhD}$, професор кафедри економіки домашніх господарств та екології ORCID https://orcid.org/0000-0001-5649-0860 gmal@hua.gr

Афінський університет Арокопіо, Греиія

Анотація. Це дослідження спрямоване на вивчення впливу практики ланцюжка поставок «останньої милі» на стійкість міст. Було проведено великий огляд літератури із передових методів логістики останньої милі, впливу електронної комериії на поставки останньої милі $і$ динаміці між державними органами і приватним бізнесом, а також ролі кінцевих клієнтів, жителів міста. Місцева влада усвідомлюють вплив на навколишнє середовище правил доставки «останньої милі» $i$ вживають заходів щзодо поліпшення якості життя своїх жителів. 3 іншого боку, підприсмства прагнуть знизити витрати на ланцюжок поставок, підвищчити ефективність $i$ запропонувати своїм клієнтам якісні послуги. Огляд практики привів до розробки конщептуальних основ, що відображають иілісну перспективу управління доставкою «останньої милі» і підкреслюють динаміку між політиками (державними органами) і приватним сектором.

Ключові слова: міський ланцююжок поставок, міське розподіл, міська логістика, доставка останньої милі, вантажні перевезення.

(C) Bakogianni Maria Aristea,

Malindretos George, 2021
УДК 338.47

JEL 018

DOI 10.31375/2226-1915-2021-2-38-64

«ДОСТАВКА ПОСЛЕДНЕЙ МИЛИ» В РАМКАХ ГОРОДСКОГО РАСПРЕДЕЛЕНИЯ И УПРАВЛЕНИЯ ЦЕПЯМИ ПОСТАВОК: ОБЗОР ПЕРЕДОВОГО ОПЫТА И КОНЦЕПТУАЛЬНЫЕ ОСНОВЫ

Мариа Аристея Бакогианни $\mathrm{PhD}$

Джорж Малиндретос

$\mathrm{PhD}$, профессор кафедры экономики домашних хозяйств и экологии

Афинский университет Арокопио, Греичия

Аннотация. Это исследование направлено на изучение влияния практики цепочки поставок "последней мили» на устойчивость городов. Был проведен обширный обзор литературы по передовым методам логистики последней мили, влиянию электронной коммеричии на поставки последней мили и динамике между государственными органами $u$ частным бизнесом, а также роли конечных клиентов, жителей города. Местные власти осознают влияние на окружаюшую среду правил доставки «последней мили» и принимают меры по улучшению качества жизни своих жителей. С другой стороны, предприятия стремятся снизить затраты на иепочку поставок, повысить эффективность и предложить своим клиентам качественные услуги. Обзор практики привел к разработке кониептуальных основ, отражаютих целостную перспективу управления доставкой «последней мили» и подчеркиваюших динамику между политиками (государственными органами) и частным сектором.

Ключевые слова: городская цепочка поставок, городское распределение, городская логистика, доставка последней мили, грузовые перевозки. 
UDC 338.47

JEL O18

DOI 10.31375/2226-1915-2021-2-38-64

\title{
«LAST MILE DELIVERIES» IN THE FRAMEWORK OF URBAN DISTRIBUTION AND SUPPLY CHAIN MANAGEMENT: REVIEW OF BEST PRACTICES AND CONCEPTUAL FRAMEWORK
}

\author{
Maria Aristea Bakogianni \\ PhD Candidate, \\ George Malindretos \\ Associate Professor, \\ ORCID https://orcid.org/0000-0001-5649-0860 \\ gmal@hua.gr \\ Harokopio University Athens, Greece
}

\begin{abstract}
This paper aims to investigate the impact of last mile supply chain practices on urban sustainability. An extensive review of literature has been conducted, on last mile logistics best practices, the impact of e-commerce on last mile deliveries, and the dynamics between the public authorities and private businesses, as well as the role of the final customers, the city dwellers. Local authorities being aware of the environmental impact of last mile deliveries issue regulations and take initiatives towards improving the quality of life for their residents. On the other hand, businesses aim at reducing supply chain costs, improve efficiency and offer quality services to their customers. The review of practices lead into the development of a conceptual framework depicting a holistic perspective of last mile deliveries management, highlighting the dynamics between policy makers (public authorities) and the private sector.

Keywords: Urban supply chain, Urban distribution, Urban Logistics, Last mile deliveries, Freight Transport.
\end{abstract}

1. Introduction. Recent literature on urban supply chain has sought to define the concepts of last mile logistics, urban distribution and urban supply chain. This leads to the promotion of a single typology and a common framework that includes all the concepts of urban supply chain. The studies recognize the lack of a common framework and typology, while at the same time efforts are being made to identify and describe in detail the role and objectives of stakeholders (municipality, enterprises, citizens) in the design and implementation of last mile logistics projects and the dynamics between them. The last mile logistics concept looks into managerial techniques, technologies, and methodologies for the diffusion of small loads over the urban fabric («capillary» distribution). This part of urban logistics is connected to and addressed by a number of problems and challenges relating to routing, freight sizes and vehicle type, parking and access restrictions, and the operation of delivery and delivery of freight, interacting with the final customer/local authority. The last mile logistics is that part of urban logistics that has the greatest impact in terms of urban sustainability, influencing pollutant emissions, noise induction, public traffic safety and overall quality of life in the city. 
While the planning of the wider urban logistics operations is more relevant to the businesses and their supply chains, the design of last mile logistics requires a more holistic approach, as it is significantly influenced by the decisions of municipalities and their urban planning approaches and implementation, and directly affects the living standards of the municipalities.

The current bibliography evaluation framework aims to give an insight into the recent research into the problems of last mile deliveries in the context of interaction between stakeholders (municipal authorities, businesses, citizens) and the sources from which the information is obtained.

\section{Review of the last research} and publications. Several researches focus on public sector efforts to modernize last mile logistics and urban supply chain as a whole, establishing new policies and regulations. Municipal authorities are in a position to introduce policies ranging from limiting access to the city centre to introducing tolls and limiting the movement of commercial vehicles to specific transit lanes. Witkowskia and Janiak (2014) look at the role of Polish local governments to improve the movement of goods and people in the city and conclude that local government does not have the functional approach to address the issues arising from freight transport, so their approach is limited to measures concerning the mobility of residents. Allen et al (2018) note that the municipal authorities have a difficult challenge to face in order to achieve a balance between increasing the efficiency of last mile deliveries and simultaneously limiting the environmental and traffic impacts associated with last mile logistics design.

The use of appropriate policies and regulations is fundamental to reducing the external effects of the last mile logistics, in particular congestion, noise and air pollution, produced by distribution activities in urban areas. In addition, information and communication technologies are very important in achieving the best results. The dissemination of sensors, the development of information technologies, the intelligent transport systems services and the fourth industrial revolution, even within cities, offer new prospects for the control of smart cities, particularly for smart mobility. Video use and data collection on vehicles, flows and traffic allow municipal authorities to modify real-time traffic conditions (Djahel, 2015). An intelligent light-signalling management system could bring about a significant improvement in the design of the last mile logistics; however a challenge for researchers, since synchronizing multiple light-signalling systems at intersections, road contributions and nodes is a complex problem of data and a large number of parameters. Ghazal (2016) presents an approach to solving this problem by using infrared sensors (IR) and distributing dynamic time slots, but it is generally accepted that enough research is needed to present a sustainable and workable plan based on this approach. The use of properly routed electric vehicles with pre-defined windows of delivery and recharging stations presented as a solution by several researchers, looking at different vehicle combinations (Schneider, 2014; Hiermann, 2016; Rezgui, 2015). 
Another valuable tool for public authorities towards fulfilling their objectives for a sustainable urban environment, are the Sustainable Urban Mobility and Sustainable Urban Logistics plans. These are strategic plans based on existing planning practices and inspired by the principles of holistic planning, stakeholders' participation and evaluation to meet people's mobility needs today and in the future, for a better quality of life in the city and its surrounding areas. The Sustainable Urban Mobility Plan (SUMP) is a generic EU driven template for policy making that aims to create a sustainable urban transport system that:

- ensures accessibility of jobs and services to everyone;

- improves the protection and safety of people in transit;

- reduces pollution, greenhouse gas emissions and energy consumption;

- increases efficiency and effectiveness of people mobility and cargo transport;

- enhances the attractiveness and quality of the urban environment.

The SULPs (Sustainable Urban Logistics Plans) are sub-sections of the SUMP aiming at the improvement of urban logistics and last mile supply chains. The SUMPs are based on a unified acceptable long-term vision for transport and mobility throughout the urban environment, which covers all modes and means of transport (public and private, passenger and freight, motor and non-engine), and behavior on movements and parking. Strategic vision provides a qualitative description of the desired future and guides the development of the appropriate planning framework. The SUMP defines specific objectives, which are aligned with the overall vision of the local government for the future of the given city. Changes and effects are measurable and relate to the hierarchy of objectives, focusing on selected performance indicators.

Urban transport pricing systems and mobility credits are recent solutions adopted in many cities to reduce the number of vehicles in the city centre or in specific urban areas. A pricing system can also be used to allow free access to periods of off-peak time, e.g. at night. Mobility credits are a special form of incentives based on licenses rather than restrictions and based on the allocation of a limited amount to each user by the municipal authority. The cities implementing the mobility credits to optimize last mile deliveries are still few and the possibilities offered by this solution deserve to be explored more in the scientific literature.

In order to achieve a sustainable last mile logistics, end consumers/residents should somehow be made aware of the impact of the existing delivery methods used in the city and their impact on the sustainability and quality of life of the city. In this way, consumers will be more flexible to accept and adopt alternative delivery methods. Crowdtasking has been discussed in the literature, using modeling and simulating tools of applying this method and the problems and impacts at the customer service level (Wang et al., 2016). Yuen et al. (2018) emphasize the need for consumers to recognize the importance and the positive effects that can result from the partly 'reverse' of the last mile logistics, where the final recipient is invited to collect the product from a predetermined point of delivery, instead of 
being delivered to the consumer's door. This requires a significant change in consumer attitudes, particularly in terms of requirements and expectations for e-commerce services.

The use of stations or points of approach is an innovative strategy to improve the efficiency and completion of the last mile, especially for the distribution of small-scale goods. This approach is based on the use of stations where goods can be stored when customers are not at home until they are able to collect them, thus avoiding the risk of unsuccessful delivery and leading to both economic and environmental benefits. In order to efficiently design such a network, it is recommended that a unified packaging system for the storage of delivered goods (parcels) should be proposed until the merchandise is received by the customer (Dell'Amico, 2012). These points may be located in residential areas, in shopping centers, central squares, etc.

Another innovative approach is that of selecting pop-station stations to pick up products from customers (Gunasekaran, 2015). This proposal is based mainly on the exploitation of smart technologies to strengthen the logistics of the last mile. A certain amount of money will be made available for remuneration to a worker according to the extra cost of travel by checking distances based on the recorded consignment history. The aim is to allocate all parcels to the stations by the workers in order to minimize the total costs paid by supply chain companies. As in other economic-sharing scenarios, the main objective of this implementation is to maximize the use of resources based on a collaborative approach.
Companies providing e-commerce services and carriers cooperating with them shall take steps to reduce delivery costs and meet the expectations of their customers. In addition to reducing costs, many of these initiatives lead to increased efficiency in the operation of supply chains and a reduction in environmental footprint (Iwan, 2016). The main methods of alternative delivery methods observed are either via vaults, where final delivery is moved one stage earlier, or by means of remote-controlled means for delivery at the customer's door.

The most common approach to optimizing last mile logistics is that of reducing the distance traveled, «requiring» the customer to fill part of the distance for the product to be picked up (Morganti, 2014). These alternative systems allow more packages to be delivered to specific locations by eliminating delivery failure, which leads to a reduction in delivery costs. The most prevalent method is the one of the Cargo Boxes (Iwan 2016, Allen 2007). This is a simple, unsupervised goods collection and delivery infrastructure (CDP), typically using automated computer-coded vaults supported by an online application in which the carrier provides customer updates on their order status (Iwan, 2016).

The use of cargo bays has been extensively assessed over the past decade, both in terms of distribution network and in terms of customer acceptance. Most of the surveys looking at the use of slots focus on developing the conceptual framework (Visser 2014, Cullinane 2009), assessing demand for this type of service (de Oliveira 2017, Iwan 2016, Weltevreden 2009, Cardenne as 2016) and the development of 
mathematical methods and models to analyze the potential cost savings in the use of these bays (Cardenas 2017, Liu 2019, Wang et al. 2014, Arnold et al. 2018). The main advantage for customers of the cargo bays is that, knowing the point of receipt, they do not have to stay at home and wait for the delivery of the product (Morganti 2014, McLeod 2006). According to Russo and Comi (2010), the use of these bays can have a number of positive effects on the city's sustainability, reducing the distance traveled, removing vehicles from the roads, reducing traffic congestion, and reducing pollutants and noise pollution.

Despite numerous advantages, when such a system is not properly designed, it can lead to inconvenience and reduced customer satisfaction by forcing them into unnecessary paths to pick up their orders. The key to the effective operation of a network of freight yards is the successful selection of the places where these infrastructure will be created (Morganti et al., 2014). Arnold et al. (2018) they reviewed the routes resulting from online purchases in the city of Antwerp. They simulated the current scenario, which concerns urban deliveries with conventional trucks and three other scenarios, which include the use of doors, the use of bicycles as a transport vehicle and a form of hybrid system. The hybrid system was re-cognized as the best-performing scenario in terms of operational and external costs. The simulation carried out was based on vehicle routing. A similar approach was used by Wang et al. (2014) with scenarios taking into account different densities in both the installed systems and the population. The above surveys suggest that using lockers is efficient when there is a high population density and a large number of orders. According to van Kolck et al. (2010), the static simulation performed by the above researchers did not take into account significant factors related to urban mobility.

The interaction between mobility and the design of a network of lockers has been of concern to a number of urban logistics researchers, mainly in the analysis of last mile logistics. In particular, the literature looks at different approaches to how to design a network of vaults, so that they do not burden the network and the infrastructure used by residents for their travel. In addition, some articles examine the attitude and reaction of residents to these new methods of delivery of a last mile. Secondary and qualitative surveys have evaluated customer motivation, added value and usability of this service, as well as the challenges in interaction between residents and freight lockers (Lemke et al., 2016; Kedia, et al., 2017; Vakulenko et al. 2018).

Carriers are looking for ways to improve the efficiency of last mile delivery and then reduce the cost of home deliveries. One of the main problems to be addressed is failed and repeated deliveries and fragmented shipments. Some carriers are attempting to resolve this problem by delivering the goods to a neighbor or other alternative party at the recipient's suggestion (Morganti et al., 2014). Others are investing in research to optimize truck routes and time schedules. Allen et al. (2018) consider the reasons behind the increasing use of light trucks and the growing demand for sustainable delivery services in London. The growing demand for home delivery services has resulted in overlapping deli- 
veries, with negative effects on the efficiency and cost of transport. This study reveals that $62 \%$ of the total service and $40 \%$ of the distance is covered by foot (Allen et al., 2018). The above conclusions reflect the serious deficiencies and high costs that will have to be addressed in order to achieve a sustainable last mile distribution service and to meet customer requirements.

In addition to efficiency-optimization methods, a more innovative approach proposes the combined use of trucks and unmanned vehicles for the delivery of goods (Boysen et al. 2018). The use of unmanned vehicles for last mile delivery could be carried out if unmanned vehicles are present on the same truck with the goods, parking the truck at a specific location for the purpose of transport and making the delivery of a last mile by unmanned vehicles from that location. This approach requires that simulations and optimizations be carried out so that they are operational and economically feasible. Another solution is that of direct public/customer involvement (crowdtasking) by stimulating customers themselves to take care of the delivery of goods to their neighbors (Wanet al., 2016). For example, when a customer receives their order, supported by appropriate technology applications, they will be able to receive their neighbors' outstanding orders. This approach requires the provision of appropriate incentives to be prepared to handle the last part of the supply chain.

The modeling and simulation used to establish an efficient last mile logistics system aims at the optimal combination of conventional and non-conventional vehicles, unmanned vehicles (drones), with a view to delivering goods in urban areas. A large part of the research in this field is oriented towards finding suitable locations for recharging unmanned vessels within urban fabric, to ensu-re the uninterrupted delivery of goods (Hong et al., 2018). Another study uses Logical Restriction Planning to combine conventional vehicles, drones, and cargo and distribution consolidation centers, in order to minimize delivery time (Ham, 2018). Baudel et al., (2016) developed a system architecture and a prototype to optimize urban freight transport routes, resulting in a $18 \%$ distance saving, a $11 \%$ time saving, with a corresponding reduction of $\mathrm{CO} 2$ emissions (Baudel et al., 2016).

Most of the innovations in urban supply chain and transport systems are implemented mainly due to the development of smart computing systems and technology applications (Sciuto, 2012). Smart IT applications include positioning technologies, retrieval and distribution of information via satellites, development of mobile applications, and intelligent collection and processing of information through the Internet of Things and large database processing tools. Smart phones are now powerful and easy to use tools that bring most of these technologies together into one device. Many researchers say future innovations in the transport sector will be directly linked to the use of mobile phones and the applications that can be developed there, providing an open channel for communication with freight operators (Petrovic, 2013).

In addition to supporting innovation in the public and private sectors, new technologies can help to achieve the objective of sustainable urban development by optimizing the last mile of lo- 
gistics. Van Duin et al. (2013) refer to the importance of using Big Data and Machine Learning to optimize the programming of last mile distributions. Their research indicates that the amount of data used and collected for deliveries in the last mile will allow forecasts to be made, thereby increasing delivery efficiency. In another survey, attempts are made to link the urban supply chain to a «natural urban internet» (Crainic and Montreuil, 2015).

Physical Internet is defined as an open global logistics system based on physical, digital and functional connectivity, through encapsulation, interconnectors and protocols, and is intended to replace current logistics models. Such a link would allow the redefinition, redesign and change of the way the supply chain as a whole is implemented (Crainic and Montreuil, 2015). Some of the challenges of this approach would be to define a new business model that would make it viable, and to define a possible new strategy and policy (Crainic and Montreuil, 2015).

An interesting issue is the last mile delivery of vulnerable products, for which no extensive research has been carried out. Some authors (Rijpkema 2014, Bogataj 2005, Al Shamsi 2014, Le 2013, Hsu 2007) analyze the problems of the transport of vulnerable products and the impact on quality degradation and losses. In addition, problems with the routing of vulnerable products to reduce the environmental impact and $\mathrm{CO} 2$ emissions from vehicles shall be addressed, using time parameters and margins. In some cases, a transport model is proposed using automated electric vehicles to deliver fresh food that minimizes kilometers while preserving product quality characteristics (Pal, 2016).

The concept of cooperative urban supply chain is an innovative approach aimed at integrating and synchronizing available resources. This approach is based on the sharing of resources, infrastructure and means of transport to optimize last mile logistics in urban areas. The idea is similar to that of cooperation between airlines at airports (De Souza, 2014). The main advantages are shared investments and shared management and cost savings, better use of resources and improved distribution and delivery performance in urban areas. Coordination is a key element of this process to ensure synergy between actors, private and public (Gunasekaran, 2015). Several researchers are approaching the development of urban cargo consolidation centers combined with smart technology tools and a bidding auction mechanism to determine the size of the demand to be met by the collaborative scheme (Handoko, 2014).

The creation of medium-sized urban cargo consolidation centers using smart informatics is proposed by Zunder (2016). In particular, it is proposed to implement IT in order to enhance the involvement of stakeholders in the design and implementation of policies aimed at improving the sustainability of urban freight transport. A variant of the concept of collective and cooperative urban supply chain proposes the delivery of small and medium-sized goods using public transport (Chatterjee, 2016). This approach helps to avoid further deterioration of traffic congestion and, at the same time, allows for the reduction of pollutants. Feasibility studies have been carried out in order to assess the viabi- 
lity of this proposal, based on a multifactor model to reduce costs, process handling time and energy consumption.

3. Best practices in urban supply chain and last mile logistics

3.1 Cooperation networks. The creation of cooperation networks, especially between carriers, is an effective practice for optimizing urban logistics (Quak, 2012). In a study of optimization and sustainability of urban freight transport in the Netherlands, and in particular in the Amsterdam region, it is pointed out that the adoption of network cooperation between carriers has reduced traffic congestion caused specifically by the last mile traditions. The significant traffic congestion caused by the last mile deliveries to freight has increased the awareness of government operators of environmental sustainability (Quak, 2012). As a result, more pressure was put on haulers and distributors to mobilize for their part for more innovation and environmental sustainability actions, such as the one of network cooperation. Several carriers in the Netherlands share the respective transport networks in order to consolidate deliveries and reduce traffic congestion caused by freight (Quak, 2012).

The TransMission Network, for example, has grouped under its umbrella of the 16 transporters traditionally covering only one area each. In order to increase cooperation, one of the partners has been used exclusively as a central hub for the integration and cross-docking of missions. The remaining carriers were allocated by type of productload and not by region. This network cooperation has resulted in fewer trucks entering Amsterdam, reduced mileage, reduced congestion, and reduced emis- sions and reduced noise nuisance in the urban area (Quak, 2012).

Another study compared the functional performance, transport costs, road use and $\mathrm{CO} 2$ emissions between two cases in the town of Bogota, Colombia, one that operates a network of cooperation and one that does not implement network cooperation. According to this study, the collective last mile deliveries seem to be beneficial for improving the urban logistics system in relation to the parameters mentioned above (Muñoz et al., 2016). As regards the quantification of the benefit, in the case of the transport cooperation network in Bogotá, there was a $25 \%$ improvement in the overall distance traveled, a $25 \%$ reduction in $\mathrm{CO} 2$ emissions, a $9 \%$ reduction in routes for the fulfillment of orders and a $10 \%$ increase in the use of urban roads. (Muñoz et al., 2016).

Given the increase in e-commerce and last miledeliveries, combined with the higher availability of technological solutions in the planning of routes, cooperation networks should have seen more as a sustainable way of delivering urban logistics (Muñoz et al., 2016). The creation of logistical cooperation networks between distributors and manufacturers can lead to wide and scalable savings in all parties involved (de Souza et al., 2014). Instead of each company delivering all orders separately to all locations, creating a collaborative model allocates tasks and maximizes resource utilization. These benefits apply to delivery scheduling, order fulfillment and capacity.

For example, trucks can be used with greater capacity utilization, distances and environmental impacts would 
be reduced and service levels improved. The implementation of this model of cooperation between carriers and manufacturers has significantly improved last mile deliveries in the urban fabric of Singapore (de Souza, R.et al., 2014). In a similar case to the City of Berlin, carriers participating in the cooperation are divided into three groups according to the nature of the products they transport: in each group, carriers shall deliver the goods to a unit acting as an urban goods consolidation center which in turn delivers the last mile on their behalf. (Sinarimbo, 2005). As a result, this model has reduced mileage between partner members by $70 \%$. Similarly, the number of trucks entering the city has decreased by $11 \%$, as have emissions and traffic congestion.

In the case of Tokyo, the implementation of cooperation networks and shared transport vehicles has significantly reduced traffic by $12 \%$ in the Marunouchi region. Total emissions of NOx also decreased by $89 \%$ (Sinarimbo, 2005). Although it is characterized as sustainable practice with significant recorded benefits in offsetting the economic and environmental impact of urban supply chain, the implementation of cooperation networks and the sharing of means of transport is not widely accepted, with shared transport vehicles, such as trucks accounting for only $1,2 \%$ of total transport vehicles in developing countries (Sinarimbo, 2005).

3.2. Change and innovation in the means of delivery. In the Netherlands, new vehicles have been introduced by the authorities in an attempt to optimize freight transport in urban areas (Van Rooijen and Quak, 2014). The idea behind these practices is that vehicles which deliver within cities should be smaller and more environmentally friendly in order to compensate for the negative effects of increasing traffic and pollution in urban areas. Examples of these initiatives are the electric boat in Utrecht used to deliver bulky goods to shops in the city without burdening roads and infrastructure with limits. This motorized ship called «beer boat» in Utrecht is currently operating and delivering to more than 60 local businesses close to water (Van Rooijen and Quak, 2014). Due to the success of the Beer Boat in reducing congestion and pollutant emissions, a second similar vehicle was created for the collection of waste (Van Rooijen and Quak, 2014). There was also a change in the modes of transport and delivery in Utrecht, where electric vehicles called «Cargohopper» are used to perform in-city distribution of pre-unified parcels (Browne M. et al., 2012).

Another example of private initiative is that of a transport company that introduced a sustainable delivery line in Portland in 2009 (Portland Oregon Gov., 2016). This company limited the use of means of transport in urban tissue, using only electrically assisted tricycles for their distributions. With this initiative, the number of last mile deliveries made by trucks fell by about 80,000 (Portland Oregon Gov., 2016). According to the same source, it is estimated that $\mathrm{CO} 2$ emissions in the city have also decreased by 18 tons.

A study conducted at the City of London Economic Center showed that the use of light trucks, with relatively upward stability in recent years, has increased significantly due to the increase in e-commerce (Allen J.et al., 2018). In 
fact, the number of light vehicles associated with fulfilling the last mile deliveries in London has increased by $70 \%$ since 1995 (Department of Transport, 2016). To meet this demand, local authorities have restructured roads, both central and non-central. The space on the streets of London has been redistributed to provide space for light commercial vehicles (such as bicycles) and to increase the space available for pedestrians (Allen J.et al., 2018). This is because $62 \%$ of the total delivery time of the last mile is for lowercase distribution, with the vehicle parked (Allen J.et al., 2018). This redistribution of London space for the reception of light vehicles and pedestrians has reduced road capacity, reduced traffic speed and increased traffic delays (Allen J.et al., 2018). We could conclude that the redistribution of roads for the reception of pedestrians and light trucks is a good practice, but to some extent it may exacerbate congestion rather than improve traffic in urban areas. On the other hand, the transition from traditional trucks to improved new technologies, trucks have reduced fuel consumption by $60 \%$ for many companies in London (Zanni A. and Brostow A., 2010). According to the same source, carbon emissions caused by freight transport are expected to decrease by 6 tons per year by 2030 in London. Taking into account the transition to fully hybrid power vehicles, London expects a one million tons reduction in carbon emissions by 2021 (Zanni A. and Brostow A., 2010).

In Berlin, last mile deliveries is supported by so-called BentoBoxes, lockers which act as delivery and receiving points (Leonardi J.et al., 2014). In parallel with these bays, electrically as- sisted bicycles were introduced to deliver the last mile from the bays to the customers' homes. These bays have been used as a focal point for urban traditions in Berlin and as collection points for customers. When acting as a collection point, customers receive automatic notification when the package is delivered to the locker, and can thus come and collect from the designated points at their convenience. This procedure benefits all stakeholders involved in the urban supply chain: the government benefits by saving money, customers benefit from greater flexibility in collection and delivery times, and transporters benefit from parcel consolidation and resulting greater efficiency (Leonardi J.et al., 2014). According to the same source, it is estimated that the use of the BentoBox reduced the need for traditional transport vehicles and promoted the use of light trucks such as electric bicycles, thus benefiting the environment and reducing emissions of pollutants (Leonardi J.et al., 2014).

Similarly, in an attempt to compensate for the environmental impact of urban logistics, the SMILE project was launched and tested in 2015 in five European cities (Navarro C. et al, 2016). This project consists of promoting the use of electric tricycles in combination with urban integration centers for last mile deliveries. This alternative system, which combines electric vehicles and cross-docking points, has led to many benefits in terms of cost and sustainability savings (Navarro et al, 2016). In the case of Barcelona, for example, the implementation of the system has reduced the distance traveled by $16000 \mathrm{~km}$ per year (Navarro et al, 2016). Fuel consumption from traditional transport ve- 
hicles has also decreased by more than 4,000 liters per year, followed by a 2-ton reduction in $\mathrm{CO} 2$ emissions (Navarro et al., 2016). In addition to the benefits for environmental sustainability, these systems also contribute to reducing the overall cost of last mile logistics. A similar system has been introduced in San Sebastian (Spain) and has led to similar benefits in terms of reducing pollutant emissions and saving fuel consumption (Rooijen and Quak 2014).

\subsection{Change in delivery destina-}

tions. Shifting the delivery location away from customers' homes seems to be among the good practices for more sustainable urban logistics (IwanS. etal., 2016). A first study conducted in Poland describes how the use of lockers and customer pick up is an efficient last mile delivery practice. It is argued that due to the pressure last mile delivery is putting to urban freight, a collection point system such as lockers would help rationalize and optimize last mile delivery. Such a system would eliminate a few constraints: the presence of both the carrier and customer at the time of delivery would no longer be required, and the risk of failed delivery and reverse logistics would decline. This would also allow for more flexible delivery times and allow for silent and low traffic night deliveries to the locker system (IwanS. etal., 2016). In Szczecin (Poland), lockers implementation in the city for customer order collection has enable local couriers to deliver $900 \%$ more parcels per day than in the case of a pure push or pull delivery system. The mileage (distance travelled per day) has decreased by $53 \%$, and total $\mathrm{CO}_{2}$ emissions have decreased by $95 \%$ per annum. Thus, it cannot be denied that collection points such as parcel lockers are a good practice when it comes to relieving the pressure of last mile delivery on urban logistics. The impact of urban logistics practices on traffic congestion and pollutants emissions have similarly been addressed in another study on Sussex, London (SongL. etal., 2009). It explains how order and collect methods, known as collection point systems, would help solve last mile related problems highlighted previously as well as reduce the rate of failed deliveries and the resulting reverse logistics (SongL. etal., 2009). The Royal mail, Parcel Force and other carriers have been using post offices as collection points for online order fulfillment, but it seems like there is still room for future improvement when it comes to implementing such last mile delivery systems in Sussex (SongL. etal., 2009).

In a similar case study of Christchurch (New Zealand), it has been argued that shifting urban deliveries from homes to pre-defined collection points can increase delivery efficiency and reduce the number of failed home deliveries. (KediaA., etal., 2017). The same source also discusses the issue of customer acceptance. It is highlighted that customers' satisfaction would not be affected by the shift in delivery location as long as the collection point is strategically located in proximity of homes, offices and other highly frequented pedestrian areas (SongL. etal., 2009).

Change of delivery location from homes to delivery points strategically located across the city seems to be a successful practice as it has also been implemented in France and Germany in order to respond to the increasing demand for last mile delivery (MorgantiE. 
etal., 2014). The largest delivery and collection points system is being managed by DHL in conjunction with the post office, with over two thousand locations operating all over Germany (MorgantiE.etal., 2014). According to the same source, these collection / delivery points in the form of locker rooms have significantly decreased the number of failed deliveries, decreased overall operational costs and increased delivery efficiency. In France, the number of lockers room has increased by $67 \%$ in four years, providing more standardized delivery networks accessible in less than ten minutes by customers for parcel pickup, thus probably not significantly decreasing customer satisfaction (MorgantiE. etal., 2014).

In London, depot to hub delivery systems have been tested as an alternative to traditional last mile delivery systems, in partnership with UPS. This strategy aims to deliver all parcels to a central hub or micro consolidation center located in busy urban areas; from the central hub, electrically powered vehicles will then deliver the goods to customers' homes. Specialists believe that such a system could create a more sustainable urban delivery by reducing pollutants emissions in urban areas (Fernhay, 2019).

Similarly in Tokyo lockers have been implemented and used in order to decrease traffic congestion and pollutants emissions related to last mile delivery vehicles (WatanabeS., 2019).

In the Netherlands, an operator called Viatim delivers parcels via neighbors. This algorithm operated system selects a neighbor nearby and sends the parcel directly to them as a collection point. This eliminates the constraint of physical presence during delivery and also provides some benefits in terms of consolidation and economies of scale by sending parcels to collection points (Glasco, 2019).

\subsection{Urban Consolidation Cent-}

res. Urban consolidation centers are among the best practices for sustainable urban logistics (VREF, 2019). Also known as transshipment centers, these are facilities ideally located outside city limits and are used to consolidate shipments in a more efficient manner before pursuing urban deliveries. In other words, instead of loading multiple large trucks under their full capacity, the trucks would first stop at the consolidation center and perform parcel consolidation depending on the intra city delivery destination. Following this exercise, smaller and fully loaded trucks would perform the delivery into the last mile area. Urban consolidation centers are among the best practices for sustainable urban logistics because these facilities provide benefits in terms of traffic reduction, loading capacity utilization as well as environmental benefits such as the reduction of $\mathrm{CO} 2$ emissions (VREF, 2019). Such facilities have already been implemented in several Dutch cities such as Nijmegen in the Netherlands (Stadsleveransen, 2013). The Binnenstadservice consolidation center started operating in Nijmegen in 2008. Since its inauguration, over 98 participants have joined the initiative and local impacts have been observed on the city. The number of large vehicles entering the city has decreased, the urban distance travelled by vehicles has decreased, the air quality has improved and the noise pollution has decreased (Quaketal., 2010). In London, a similar urban con- 
solidation center has been built in 2009 in order to offset the negative effects of higher urban freight on the environment (Browneetal., 2012). All deliveries are being consolidated at the facility located at the entrance of London, and last mile deliveries are conducted using smaller vehicles such as tricycles and electric vehicles (Browneetal., 2012). After its implementation, the urban consolidation in London has significantly the decreased the number of trucks entering the city and a reduction of $75 \%$ of $\mathrm{CO}_{2}$ emissions have been observed (Hanaoka et al., 2011).

According to the same source, a similar project was implemented in Tokyo (Japan) and has been operating since 2004. All parcels are consolidated and transportation is shifted to low emissions vehicles to complete order deliveries within the city of Tokyo (Browne M. et al., 2012). In France, the implementation of a consolidation center in La Rochelle near Paris has significantly improved urban organization in terms of traffic (Browne M. et al., 2012). The facility has known such a success that its management has been assigned to a public transportation operator for the first time in history of France, where goods transportation is usually awarded to private entities. Following La Rochelle, other cities in France have also implemented smaller scale consolidation centres, such as Bordeaux, Lyon and Rouen (Browne et al., 2012).

This practices being very popular to ensure more sustainable urban logistics, urban consolidation centers have been implemented in other major cities such as Padua (Leonardietal., 2014). Over one hundred thousand deliveries transit each year from couriers operating in the city (Leonardietal., 2014). According to the same source, the use of the city-port center in Padua has benefited urban logistics in terms of better freight efficiency, decreased pollutants emissions as well as decreased distance travelled by vehicles due to better consolidation of parcels. Thanks to its success in improving urban logistics, this model has then been replicated in other Italian cities such as Bescia and Modena (Leonardietal., 2014).

3.5. Relocation of traffic generators. Traffic generators are companies, organizations or facilities that require a large number of inbound and/or outbound deliveries and shipments in order to operate. These include but are not limited to airports, ports, hospitals, large manufacturing companies and other large companies. The strategic relocation of such traffic generators to more adapted locations can improve the freight network and reduce the negative impact of frequent deliveries on urban logistics. These traffic generators are usually relocated to areas outside the city limits in order to shift the implied traffic outside urban areas. The relocation of traffic generators can thus reduce urban traffic congestion, as well as provide other economic benefits such as the reduction of urban land use cost (VREF, 2019).

The increasing urban population density and complexity provides incentives to implement innovative logistics systems and models in order to solve the last mile delivery issue ( $\mathrm{PwC}, 2019)$. A reliable solution according to the same source would be the use of «monopolies», which would force urban logistics providers to define and create exclusive and clustered supply areas for each 
city/region. In the case of Chicago, policy makers have for instance relocated a large market (South water) away from the west side neighborhood of the city to Chicago's international wholesale market at the city borders (VREF, 2019). The relocation of traffic generators away from the city center and into dedicated locations has led to the creation of freight villages. These represent the clusters of large traffic generators occupying a single location at the city limits. Strategically located, freight clusters at the limits of urban areas provide logistical benefits in terms of consolidation and efficiency (Hesse, 2016). Such measures optimize the use of land, provide benefits in terms of consolidation and management, improve operational efficiency, decrease intra city traffic, as well as increase economies of scale (VREF, 2019). Similar freight villages are operating in Portland, Seattle, Santiango (Chile) as well as Frankfurt (Holguínetal. 2012).

3.6. Vehicle restrictions. In order to offset the traffic congestion caused by the rise of last mile logistics, another initiative would be to impose time restrictions on delivery times (VREF, 2019). This strategy would restrict the timings at which deliveries can take place and could even ban deliveries at certain times of the day and night. Such measures would mainly improve traffic congestion and parking availability in residential and busy areas during peak hours (VREF, 2019). According to the same source, banning deliveries at peak hours would for instance highly benefit traffic congestion and parking availability. Similarly, allowing deliveries to take place at night would alleviate traffic congestion during daytime when it is the highest. Such initiatives have been introduced in Paris, London, Athens and many more European cities (YannisG. etal., 2006). In Athens (Greece) for instance, the timing restrictions on urban delivery has lead to traffic and environmental improvements. The average road speed has increased (reflecting lower congestion) and $\mathrm{CO} 2$ emissions have decreased (YannisG. etal., 2006). In another study, it is similarly suggested that banning delivery on peak hours would improve parking availability (Holguinetal., 2005).

Delivery restrictions initiative have already been implemented inLasi (Romania) as part of the CIVITAS program for sustainable urban logistics (RooijenandQuak, 2014). Deliveries have been restricted to either early morning or late evening, excluding day time peak hours. This system has led to a decrease in traffic congestion during peak hours, and the number of delivery vehicles on roads during day time has decreased from 109 on average in 2009 to 33 in 2012 (Velazquez, 2013).

A study conducted by PwC 2010 has compared the nature and scope of urban access restrictions among more than 400 European cities. It has been showed that the primary objective of restrictions implementation is environmental concerns (64\%), followed by traffic congestion reduction (35\%). The targeted vehicles are in $29 \%$ freight transportation vehicles, $8 \%$ private vehicles, and $61 \%$ both private and freight vehicles (PWC, 2010). There are several types of restrictions that can be applied to vehicles, but according to the same source, toll ring restrictions (also known as congestion fee) with an applicable fee per trip is the most widely used type of 
restriction and applies to $75 \%$ of freight transportation vehicles. These are used to regulate the access to cities. Other measures include (but are not limited to) vehicle size and weight restrictions that translate into the use of banners at the entrance of urban areas, such as the height detection mechanism in Doha, Qatar (Qatar Traffic Tech Group 2013).

In Brighton (England), a highly busy area in the heart of the city has been completely pedestrianized and all vehicles have been restricted access to the area. This initiative has successfully decreased urban traffic in the city and was well accepted by businesses in the area. Pedestrianization of streets within the cities might also promote the use of light goods vehicles such as electrical bikes to perform last mile delivery, as these are the only type of vehicles that can access such areas. As a result, such an initiative might probably decrease the overall pollutants emissions and improve air quality in urban areas.

In Amsterdam, a vehicle ban has been put on delivery trucks over 7,5 tons. Following this measure, the number of urban deliveries conducted by light weight trucks has decreased by $43 \%$ (Sinarimbo, 2005).

In New York, parking restrictions have been imposed and parking spaces have been exclusively allocated to commercial vehicles during certain time windows in order to reduce traffic congestion in Columbus Avenue (VREF, 2019). This initiative has reduced the number of delivery vehicles illegally parked on travel lanes by $21 \%$. As a result, it has significantly reduced traffic congestion in the area and increased travel speed. As part of the FIDEUS project, restrictions on vehicle noise levels have been tested in Barcelona and other European cities. In the case of Barcelona, this initiative has decreased urban noise levels from $79 \mathrm{Vb}$ to $73 \mathrm{Vb}$ (European Commission, 2019).

3.7. Truck routes. A different type of vehicle restriction is the creation of truck routes. This is a type of vehicle restriction that specifies if certain routes can be used exclusively by larger vehicles such as trucks. These can be used to provide alternative routes to trucks in case those have been restricted access to certain routes inside the urban areas. Such an initiative has been implemented in the city of Tallinn (Estonia), where special "corridors» have been created and dedicated to freight transportation around the city limits (Rooijen, 2014). After its implementation, $40 \%$ of large transportation vehicles have been using the corridor, which led to less traffic congestion in the city (RooijenV. QuakH., 2014). According to the same source, low emission zones have been defined In Utretch (Netherlands). These impose an access restriction on noncompliant vehicles such as larger and older heavy goods vehicles. Since its effective enforcement date as part of the CIVITAS program in Europe, this measure has considerably reduced pollutants emission and traffic congestion in the low emission zone (RooijenV. QuakH., 2014).

3.8. Smart technologies and media. In Basel (Switzerland) exhibition center, a tool has been made available in order to increase urban logistics efficiency (Leonardi J. et al., 2014). This tool is an online system on which suppliers, carriers and transportation operators need to $\log$ in and enter all information relevant to planned last mile deliveries, 
seven days in advance to the day the delivery will be performed (Leonardi J. et al., 2014). Once the delivery has to be performed, the delivery vehicle needs to check in at the designated check point in the delivery area in order to verify its identify and unlock a parking space as well as other machine generated insight on the optimal delivery routes. Significant reductions in traffic congestion have been observed since its implementation, and lead times have been considerably reduced thanks to the automatic billing and invoicing related to operations (Leonardi J. et al., 2014). Apart from increasing efficiency of urban deliveries and all its aspects, such a tool will also provide an opportunity for monitoring and continuous improvement as it can build databases to be used later on for analysis (LeonardiJ. etal., 2014).

In Utrecht (Netherlands), a standardized communication plan of traffic disruptions was tested and implemented as part of the CIVITAS program (Civitas, 2013). This initiative consists of communicating in a standardized manner and from a single media channel any type of roadwork and other infrastructure work that might cause traffic delays in the city. According to the same source, this initiative has decreased the number of vehicles on roads during peak hour by $4 \%$.

In the case of London, considerable progress has been made with the use of new technologies (Zanniк $\alpha$ Brotow, 2010). These include smart routing solutions as well as delivery planning and vehicle tracking, directly installed into freight vehicles. Many freight companies have implemented such a system and a consequent reduction of 10 $\%$ pollutants has been observed.
3.9. Role of freight mobility in city mapping. The consideration of freight into the mapping of cities is a widely used strategy to improve traffic and overcome last mile delivery challenges, especially among recently built cities where changing the city mapping does not require rebuilding large areas and as a result heavy investments (VREF, 2019). Such initiative rely on the improvement of infrastructure prior to the design phase in order to optimize mobility and as a result improve traffic. An example of such practices is the use of ring roads, which are bypasses meant for freight transportation vehicles. These bypasses enable vehicles such as trucks to move out of the city towards the highway through a bypass road or ring road in order to avoid traffic and reduce congestion. Typical examples of bypasses include the orbital network in Sydney, as well as similar infrastructure in Atlanta (VREF, 2019). When mapping the configuration of a new city or area within a city, the shape and size of roads is also considered in order to accommodate last mile logistics in a more efficient way. This translates into the design of new or upgraded roads with specific geometrical designs such as round corners to enable larger vehicles to take turns more easily, especially when there is low availability of space. By making the radius of the turn larger and round shaped, it removes space constraints and decreases traffic congestion. Another example of freight consideration in city mapping is the creation of ramps on sidewalks in order to enable forklifts to go up and down the sidewalk more easily. This makes the loading and unloading of delivered goods more effi- 
DEVELOPMENT OF MANAGEMENT

AND ENTREPRENEURSHIP METHODS ON TRANSPORT, № 2 (75), 2021
РОЗВИТОК МЕТОДІВ

УПРАВЛІННЯ ТА ГОСПОДАРЮВАННЯ

НА ТРАНСПОРТІ, № 2 (75), 2021 cient by easing the process of moving the forklift up and down the sidewalk.

Similarly in Barcelona and as part of the CIVITAS program, multi-use lanes have been implemented in order to reduce traffic congestion (Civitas, 2011). This system consists of having road lanes than can be used as traditional roads and converted into parking space, bus lanes or unloading space for delivery vehicles. In Barcelona, the multiuse lanes are used as bus lanes during peak hours, and then convert into unloading spaces for delivery vehicles outside of peak hour. According to the same source, this system has significantly reduced traffic congestion by $20 \%$. Similarly in the case of London, the use of dual roads by allowing freight vehicles to use bus lanes has decreased the average of trucks on the roads and as a result decreased total $\mathrm{CO} 2$ emissions by $50 \%$ (ZanniandBrotow, 2010).

\section{Conclusions and summary of}

impacts. Based on the review of literature, e-commerce has a direct and significant impact on urban logistics. Indeed, there has been a shift in the way urban logistics are conducted and many initiatives and systems can be flagged as best practices in order to offset the economic, social and environmental impact of e-commerce on urban areas.

The first best practice that has been the most observed is the use of urban consolidation centers or transshipment points. There are large facilities located at the city limits where all deliveries converge in order to be consolidated into more efficient shipments. The consolidation can be done based on the destination, the type of parcels or the scheduled delivery time. This way, vehicles are loaded in a more efficient man- ner and the use of space within the vehicles is optimized. As a result, less vehicles are needed to execute the same number of deliveries that would have been fulfilled without the consolidation center. The distance mileage is decreased and the overall delivery efficiency is increased. The presence of such consolidation centers in urban configurations will show that the city considered has adapted its urban configuration to the rise of e-commerce.

The second best practice observed is the shift in transportation modes from traditional trucks to smaller light goods vehicles such as electrical bikes and tricycles. This is because last mile deliveries have increased traffic in urban areas, which has increased gas emissions, traffic congestion and noise disturbance. In terms of urban configuration, this would imply that cities have been creating more light good vehicles friendly roads such as cycling trays, as well as recharging stations to fuel electrical vehicles. This would also justify that light goods vehicles would have been made available for public use in urban areas.

Another best practice for last mile delivery is the shift of delivery location from homes to other delivery and/or collection points. Such systems help decrease the risk of failed deliveries as well as decrease traffic congestion as delivery times become more flexible. As a result, the presence of delivery and/or collection points such as lockers within cities would display the impact e-commerce has had on urban configurations.

The relocation of large traffic generators has also been identified as one of the best practices when it comes to last mile delivery. These include any large businesses that require a large 
and/or frequent deliveries to operate. These businesses are being relocated to dedicated areas usually at the outer limits of the city in order to form clusters of traffic generators. By doing so, a large portion of traffic is relocated away from the urban area thus reducing congestion. Such a strategy can also improve consolidation as most deliveries are being conducted towards / outwards the same cluster of businesses. The presence of such freight villages nearby cities will show the impact of e-commerce on the city's urban configuration.

The use of collaborative networks among carriers is becoming a best practice to increase the efficiency of last mile delivery. By sharing transportation networks, carriers can benefit from each other's vehicles, routes and technology. Consolidation and planning can as a result be improved and become more efficient, thus reducing traffic congestion and improving overall operational efficiency. In Amsterdan and Bogota for instance, the rise of e-com-merce has increased environmental concerns and sustainability awareness, which has led to the implementation of more collaborative networks among carriers. These measures have significantly improved urban areas by decreasing traffic congestion and pollutants emissions. In terms of urban configuration, it can be considered that the market presence of operators facilitating network collaboration will show the impact of e-commerce on the configuration of the city.

Another widely used strategy to improve last mile logistics is to put a variety of restrictions on freight transportation vehicles. These include for example restriction on weight, size, height, engine and delivery time. By doing so, last mile induced urban traffic congestion decreases during certain periods (depending on the type of restriction imposed), gas emissions decrease, noise pollution improves and the availability of parking increases when access is being restricted. In terms of urban configuration, this practice will be observed via the presence of road signs, parking restrictions signs and tolls, toll rings and other signs displaying the various restriction policies.

The implementation of vehicle restrictions is a good practice and so is the implementation on the other hand of truck routes and freight transportation vehicles dedicated roads. Indeed, the use of corridors and routes for freight transportation vehicles can decrease traffic congestion in urban areas as well as decrease the distance travelled. The presence of truck routes and other corridors in and around the cities will show another impact e-commerce has had on urban configurations.

In the era of technology, the use of IT tools is an unavoidable practice to improve last mile logistics. Although it is still not widely uses due to many implementation barriers, such solutions could increase collaboration between all stakeholders involved in last mile logistics. It would also benefit the planning and scheduling of deliveries with real time information sharing, thus directly improving the overall efficiency of last mile deliveries. Such tools would be observable via the presence of connected tolls in the urban areas.

Finally yet importantly, the consideration of freight transportation in the city planning and mapping itself is a good practice for last mile logistics optimization. This translates for instance 
into the design of roads with rounded and larger turns to better accommodate trucks, as well as other minor considerations such as sidewalks with ramps to make the loading and unloading of forklifts more efficient.The presence of such features in city characteristics will show the impact of e-commerce on its urban configuration.

This conceptual framework (figure 1) was developed on the basis of the analysis carried out in this paper, with a view to identifying measures and interventions to optimize last mile logistics. The most important factor determining the importance and the size of last mile logistics is the rate of Internet penetration and, as a result, the frequency of use of electronic commerce services. Provided that the rate of Internet penetration is high, then the impact of e-commerce on traffic congestion should be determined, as it is directly related to last mile practices and is an important factor in urban areas. High levels of traffic and congestion confirm the importance of the impact of e-commerce on the urban supply chain. The involvement of the municipal authorities in the organization and regulation of the urban supply chain should then be verified. Municipal authorities should be aware of the impact of last miles logistics on the entire urban supply chain and willing to implement new measures to mitigate the effects and improve the overall performance of urban logistics. The active involvement of municipal authorities can be confirmed by the existence of regulations on goods and transport, measures and environmental sustainability policies, as well as other measures adopted, such as green city initiatives.
There is a large number of researches looking at the sustainability of last mile logistics, most of which highlight the problems and obstacles to achieving real sustainability in this sector. Traffic congestion, pollutant emissions and negative economic impacts are some of the disadvantages of last mile logistics, as they are usually carried out, without aspirations for integration and cooperation between businesses, or between municipal authorities and residents/customers. In general, the literature on the sustainability of the last mile's logistics examines the problem from the perspective of the three stakeholders, municipal authorities, private companies and customers/residents.

The bibliography investigating the supply chain of the last mile from the public sector's point of view highlights the importance of the implementation and the impact of the regulations, strategies and policies followed to regulate e-commerce, while trying to improve the sustainability of the last mile's logistics, insofar as it affects the living standards of the inhabitants. Municipal authorities should ensure the involvement of all stakeholders in decision-making and policy planning processes.

The private sector is focused on reducing the cost of logistics operations in the last mile, as it currently represents around $28 \%$ of the cost of supply chain (Wang 2016). In addition, there is a continuous evaluation of innovations and alternative methods to improve the performance of the functions associated with last mile logistics. The study of the application of technologies emphasizes the importance of smart IT systems and mobility support systems, which play an important role in the implementation of 
innovative solutions, the development of synergies between enterprises, interaction and interactivity between stakeholders and the effectiveness of functions through modelling and simulation. The importance of interaction between customers and businesses is of great interest in literature, in an effort to understand and evaluate the reaction, attitude and value for customers of the last mile delivery by assessing the many available delivery methods that are or will be applied in the future. An important point to consider is to avoid negative effects on the customer's experience of any change or introduction of new methods, which should pre-empt the right promotion, information and in some cases customer training. In conclusion, sustainability has three dimensions: economic, social and environmental. Economic sustainability is addressed by optimizing the efficiency of the last mile's logistics operations. Social and environmental sustainability is achieved by the introduction of tools and technologies in the last mile logistics which help to reduce traffic congestion in urban areas, emissions and noise, by using for example drones and/or electrically powered vehicles.

Optimizing the management and routing of transport is a very important area of research carried out to optimize last mile logistics. Optimization techniques can be applied in various aspects and can reduce external impacts in the context of smart logistics. Real-time data collection and analysis, forecasting methods and decision support systems continue to be the main areas of research to make last mile distribution systems more efficient.

Innovations that could reduce the impact of last mile logistics on urban sustainability can be divided into five main categories: innovative commercial vehicle technologies, stations or points of approach, collaborative models and optimization of transport management and routing. Each of them has advantages and gaps that can be considered research opportunities.

Combining these innovations will create a smart logistics system. However, there is still a great deal of research to be done, particularly on the use of innovative vehicle technologies. For example, electric vehicles require more study to improve or new technologies that can provide greater autonomy at lower cost. Hydrogen combustion vehicles (FCEVs) are in a mature phase and are already on the market. However, most cities lack the appropriate supply infrastructure, and there is still a need for harmonization of the regulations governing for using and operate this type of engine between EU countries.

Autonomous vehicles are still in the process of testing for the improvement of hardware and software systems. In particular, the latest research projects focus on software systems, studying algorithms that can improve safety performance and decision support systems for managing hazardous situations. Unmanned drones can be studied for the use of self-contained or remote driving with specific algorithms. The stations or points of approach of these systems require further research to optimize storage capacity so that they can cope with the high demands expected in the future. In addition, it is useful to identify the best location within the city that can reduce environmental impact.

The implementation of innovation 
in the process of public policy planning and infrastructure development is one of the areas where it is still necessary to explore and study new strategies to reduce the external-environmental impact of last mile logistics. The permitted traffic time frames, the traffic management systems with sensors, the intelligent management of light signals, the charging systems for urban transport and the model of mobility credits are very interesting approaches which require a more in-depth analysis.

A smart city should use innovative approaches to the problem of last mile tradition. The increase in express deliveries, the increasing of online sales, the new information and communication technologies, as well as the innovations developed in the context of the Fourth Industrial Revolution, allow the recove- ry of a huge amount of data produced by what is called the Internet of Things and interconnects infrastructure, devices and vehicles, are factors that must be taken into account by the actors involved in the movement of goods within the urban fabric. One of the main aims of an intelligent city is to significantly reduce the external impact of the last mile's delivery activities and to burden its environment. The commitment and cooperation between private and public actors to design, develop and implement solutions and approaches is indispensable for achieving a sustainable last mile logistics.

\section{REFERENCES}

1. Al Shamsi, A.; Al Raisi, A.; Aftab, M. Pollution-Inventory Routing Problem with Perishable Goods. Logist. Oper. Supply Chain Manag. Sustain. 2014, 585-596.

2. Allen, J., Piecyk, M., Piotrowska, M., McLeod, F., Cherrett, T., Ghali, K., Nguyen, T., Bektas, T., Bates, O., Friday, A. and Wise, S., 2018. Understanding the impact of e-commerce on last-mile light goods vehicle activity in urban areas: The case of London. Transportation Research Part D: Transport and Environment, 61, pp.325-338.

3. Arnold, F.; Cardenas, I.; Sörensen, K.; Dewulf, W. Simulation of B2C e-commerce distribution in Antwerp using cargo bikes and delivery points. Eur. Transp. Res. Rev. 2018, 10, 2.

4. Baudel, T., Dablanc, L., Alguiar-Melgarejo, P., and Ashton, J. Optimizing urban freight deliveries: From designing and testing a prototype system to address in greal life challenges. Transportation Research Procedia (2016), 170-180. Tenth International Conference on City Logistics 17-19 June 2015, Tenerife, Spain.

5. Bogataj, M.; Bogataj, L.; Vodopivec, R. Stability of perishable goods in cold logistic chains. Int. J. Prod. Econ. 2005, 93-94, 345-356.

6. Boysen, N.; Briskorn, D.; Fedtke, S.; Schwerdfeger, S. Drone delivery from trucks: Drone scheduling for given truck routes. Networks 2018, 72, 506-527. 
7. Browne, M., Allen, J., Nemoto, T., Patier, D. and Visser, J., 2012. Reducing social and environmental impacts of urban freight transport: A review of some major cities. Procedia-Social and Behavioral Sciences, 39, pp.19-33.

8. Cardenas, I.; Borbon-Galvez, Y.; Verlinden, T.; Van de Voorde, E.; Vanelslander, T.; Dewulf, W. City logistics, urban goods distribution and last mile delivery and collection. Compet. Regul. Netw. Ind. 2017, 18, 22-43.

9. Liu, C.; Wang, Q.; Susilo, Y.O. Assessing the impacts of collection-delivery points to individual's activity-travel patterns: A greener last mile alternative? Transp. Res. Part E Logist. Transp. Rev. 2019, 121, 84-99.

10. Chatterjee, R.; Freulich, C.; Edelkamp, S. Optimizing Last Mile Delivery using Public Transport with Multi-Agent based Control. In Proceedings of the 2016 IEEE 41st Conference on Local Computer Workshop, Dubai, United Arab Emirates, 7-10 November 2016.

11. CIVITAS Initiative Co-Financed by European Union, 2011. Available online: http://civitas.eu

12. T.G. Crainic and B. Montreuil. Physical internet enabled interconnected city logistics. Technical Report CIRRELT-2015-13, CIRRELT, 2015.

13. Cullinane, S. (2009) "From bricks to clicks: the impact of online retailing on transport and the environment", Transport Reviews, 29 (6), p. 759-776.

14. de Oliveira, L.K.; Morganti, E.; Dablanc, L.; de Oliveira, R.L.M. Analysis of the potential demand of automated delivery stations for e-commerce deliveries in Belo Horizonte, Brazil. Res. Transp. Econ. 2017, 65, 34-43.

15. de Souza, R., Goh, M., Lau, H.C., Ng, W.S. and Tan, P.S., 2014. Collaborative urban logistics-synchronizing the last mile a Singapore research perspective. Procedia-Social and Behavioral Sciences, 125, pp.422-431.

16. Dell'Amico, M.; Hadlidimitriou, S. Innovative logistics model and containers solution for efficient last mile delivery. Procedia Soc. Behav. Sci. 2012, 48, 1505 1514.

17. Djahel, S.; Doolan, R.; Muntean, G.M.; Murphy, J. A communications-Oriented Perspective on Traffic Management Systems for Smart Cities: Challenges and Innovative Approaches. IEEE Commun. Surv. Tutor.2015, 17, 125-151.

18. Freight Innovative Delivery in European Urban Space - TRIMIS - European Commission. (2019, October 10). Retrieved December 23, 2019, from https://trimis.ec.europa.eu/project/freight-innovative-delivery-european-urbanspace\#tab-outline

19. Ghazal, B.; ElKhatib, K.; Chahine, K.; Kherfan, M. Smart Traffic Light Control System. In Proceedings ofthe 3rd International Conference on Eletrical, Electronics, Computer Engineering and Their Applications(EECEA), Beirut, Lebanon, 21-23 April 2016 
20. Glasco, J. (2019). Last Mile Delivery Solutions in Smart Cities and Communities. Retrieved December 23, 2019, from https://hub.beesmart.city/solutions/en/smartmobility/last-mile-delivery-solutions-in-smart-cities

21. Gunasekaran, A.; Subramanian, N.; Raham, S. Green supply chain collaboration and incentives: Current trends and future directions. Transp. Res. Part E Logist. Transp. Rev. 2015, 74, 1-10.

22. Ham, A. M. (2018). Integrated scheduling of m-truck, m-drone, and m-depot constrained by time-window, drop-pickup, and m-visit using constraint programming. Transportation Research Part C: Emerging Technologies, 91:1-14

23. Hanaoka, S. and Regmi, M.B., 2011. Promoting intermodal freight transport through the development of dry ports in Asia: An environmental perspective. Iatss Research, 35(1), pp.16-23.

24. Handoko, S.D., Nguyen, D.T. and Lau, H.C., 2014, August. An auction mechanism for the last-mile deliveries via urban consolidation centre. In 2014 IEEE International Conference on Automation Science and Engineering (CASE) (pp. 607-612). IEEE.

25. Hesse, M., 2016. The city as a terminal: The urban context of logistics and freight transport. Routledge.

26. Hiermann, G.; Puchinger, J.; Ropke, S.; Hartl, R.F. The Electric Fleet Size and Mix Vehicle Routing Problem with Time Windows and Recharging Stations. Eur. J. Oper. Res. 2016, 252, 995-1018.

27. Holguin-Veras, J., Polimeni, J., Cruz, B., Xu, N., List, G., Nordstrom, J. and Haddock, J., 2005. Off-peak freight deliveries: Challenges and stakeholders' perceptions. Transportation Research Record, 1906(1), pp.42-48.

28. Hong, I., Kuby, M., Murray, A.T., 2018. A range-restricted recharging station coverage model for drone delivery service planning. Transport. Res. Part C: Emerg. Technol. 90, 198-212.

29. Hsu, C.I.; Hung, S.F.; Li, H.C. Vehicle routing problem with time-windows for perishable food delivery. J. Food Eng. 2007, 80, 465-470.

30. Iwan, S., Kijewska, K. and Lemke, J., 2016. Analysis of parcel lockers' efficiency as the last mile delivery solution-the results of the research in Poland. Transportation Research Procedia, 12, pp.644-655.

31. Kedia, A., Kusumastuti, D. and Nicholson, A. (2017). Acceptability of collection and delivery points from consumers' perspective: A qualitative case study of Christchurch city. Case Studies on Transport Policy, 5(4), pp. 587-595.

32. Le T. V. and. Ukkusuri S. V, Crowd-shipping services for last mile delivery: Analysis from survey data in two countries, 2018, [online] Available: https:/larxiv. org/abs/1810.02856 
33. Leonardi, J., Browne, M., Allen, J., Bohne, S. and Ruesch, M. (2014). Best Practice Factory for Freight Transport in Europe: Demonstrating how 'Good' Urban Freight Cases are Improving Business Profit and Public Sectors Benefits. Procedia - Social and Behavioral Sciences, 125, pp.84-98.

34. McLeod, F., Cherret, T. and Song, L. (2006), «Transport impacts of local collection delivery points», International Journal of Logistics Research and Application, Vol. 9 No. 3, pp. 307-17.

35. Morganti, E., Seidel, S., Blanquart, C., Dablanc, L. and Lenz, B. (2014). The Impact of E-commerce on Final Deliveries: Alternative Parcel Delivery Services in France and Germany. Transportation Research Procedia, 4, pp.178-190.

36. Muñoz-Villamizar, A., Montoya-Torres, J.R., and Vega-Mejia, C.A., 2016. On the impact of collaborative strategies for goods delivery in city logistics. Production Planning \& Control, 27(6), pp.443-455.

37. Muñoz-Villamizar, A., Montoya-Torres, J.R. and Vega-Mejía, C.A., 2015. Noncollaborative versus collaborative last-mile delivery in urban systems with stochastic demands. Procedia CIRP, 30, pp.263-268.

38. Navarro, C., Roca-Riu, M., Furió, S. and Estrada, M., 2016. Designing new models for energy efficiency in urban freight transport for smart cities and its application to the Spanish case. Transportation Research Procedia, 12, pp.314-324.

39. Pal, A.; Kant, K. SmartPorter: A Combined Perishable Food and People Transport Architecture in Smart Urban Areas. In Proceedings of the 2016 IEEE International Conference on Smart Computing (SMARTCOMP), St. Louis, MO, USA, 18-20 May 2016.

40. Petrovic, O.; Harnisch, M.J.; Puchleitner, T. Opportunities of mobile communication system for applications in last-mile logistics. In Proceedings of the 2013 IEEE International Conference on Advanced Logistics and Transport (ICALT), Sousse, Tunisia, 29-31 May 2013.

41. Quak, H.J., 2012. Improving urban freight transport sustainability by carriersBest practices from The Netherlands and the EU project CityLog. Procedia-Social and Behavioral Sciences, 39, pp.158-171.

42. Rezgui, D.; Aggoune-Mtalaa, W.; Bouziri, H. Towards the electrification of urban freight delivery using modular vehicles. In Proceedings of the 2015 IEEE International Conference on Service Operations and Logistics (SOLI), Hammamet, Tunisia, 15-17 November 2015.

43. Rijpkema, W.A.; Rossi, R.; Van der Vorst, J.G.A.J. Effective sourcing strategies for perishable product supply chains. Int. J. Phys. Distrib. Logist. Manag. 2014, 44, 494-510.

44. Russo, F. and Comi, A., 2010. Measures for sustainable freight transportation at urban scale: expected goals and tested results in Europe. Journal of Urban Planning and Development, 137(2), pp.142-152. 
45. Schneider, M.; Stenger, A.; Goeke, D. The Electric Vehicle-Routing Problem with Time Windows and Recharging Stations. Transp. Sci. 2014, 48, 500-520.

46. Sciuto, D. Research in smart cities: Mobility, energy, infrastructure. In Proceedings of the Meeting the Construction of a Smart City: Model for the Sustainability of Medium-Size Cities, Piacenza, Italy, 20 April 2012.

47. Sinarimbo, N.G., 2005. Freight transport management in the Central Business District: An empirical analysis of traffic and environmental impacts of cooperative delivery system (Doctoral dissertation, Thesis. Tokyo University).

48. Song, L. et al. (2009) 'Addressing the Last Mile Problem: Transport Impacts of Collection and Delivery Points', Transportation Research Record, 2097(1), pp. 9-18. Doi: 10.3141/2097-02.

49. Stads leveransen (2013) The micro terminal Lindholmen in Gothenburg, in: BESTFACT Best Practice Handbook.

50. Vakulenko, Y.; Hellström, D.; Hjort, K. What's in the parcel locker? Exploring customer value in e-commerce last mile delivery. J. Bus. Res. 2018, 88, 421-427.

51. Van Duin, J.H.R.; Tavasszy, L.A.; Quak, H.J. Towards E(lectric)-urban freight: First promising steps in the electric vehicle revolution. Eur. Transp. 2013, 54, 119.

52. Van Kolck, A.H. Multi-Agent Model for an Urban Distribution Centre; Delft University of Technology: Delft, The Netherlands, 2010.

53. Van Rooijen, T. and Quak, H., 2010. Local impacts of a new urban consolidation centre-the case of Binnenstad service. nl. Procedia-Social and Behavioral Sciences, 2(3), pp.5967-5979.

54. Van Rooijen, T. and Quak, H., 2014. City logistics in the European CIVITAS initiative. Procedia-Social and Behavioral Sciences, 125, pp.312-325.

55. Velazquez Valoria, I. et al. (2013). FINAL EVALUATION REPORT D10.3 Evaluation \& Analysis, CIVITAS ARCHIMEDES. CIVITAS Website (2012). www.civitas.eu.

56. Visser, J., Nemoto, T. and Browne, M., 2014. Home delivery and the impacts on urban freight transport: A review. Procedia-social and behavioral sciences, 125, pp.15-27.

57. Wang, X.; Zhan, L.; Ruan, J.; Zhang, J. How to choose «last mile» delivery modes for E-fulfillment. Math. Probl. Eng. 2014.

58. Wang, Y.; Zhang, D.; Liu, Q.; Shen, F.; Lee, L.H. Towards enhancing the last-mile delivery: An effective crowd-tasking model with scalable solutions. Transp. Res. Part E Logist. Transp. Rev. 2016, 93, 279-293.

59. Watanabe, S. (2019, February 3). Who solves last mile problem in Japan? Retrieved December 23, 2019, from http://watanabe-rc.com/2018/03/03/whosolves-last-mile-problem-in-japan/ 
60. Weltevreden, J.W.J.; Rotem-Mindali, O. Mobility effects of b2c and c2c e-commerce in the Netherlands: A quantitative assessment. J. Transp. Geogr. 2009, 17, 83-92.

61. Witkowski, J., Kiba-Janiak, M., 2014. The Role of Local Governments in the Development of City Logistics, Procedia - Social and Behavioral Sciences, Vol. 125, Elsevier, pp. 373-385.

62. Yannis, G., Golias, J. and Antoniou, C., 2006. Effects of urban delivery restrictions on traffic movements. Transportation Planning and Technology, 29(4), pp.295-311.

63. Yuen, K.F.; Wang, X.; Ng, L.T.W.; Wong, Y.D. An investigation of customers' intention to use self-collection services for last-mile delivery. Transp. Policy 2018, 66, $1-8$

64. Zanni, A.M. and Bristow, A.L., 2010. Emissions of CO2 from road freight transport in London: Trends and policies for long run reductions. Energy Policy, 38(4), pp.1774-1786.

65. Zunder, T.; Aditjandra, P.; Schoemaker, J.; Laparidou, K.; Vaghi, C.; Osterle, I. Engaging City Stakeholders to Achieve Efficient and Environmentally Friendly Urban Freight Movements. In Towards Innovative Freight and Logistics; John Wiley \& Sons, Inc.: Hoboken, NJ, USA, 2016.

Article received 01.06.2021

Reference a JournalArtic: Bakogianni, Maria Aristea \& Malindretos, George (2021). Last mile deliveries in the framework of urban distribution and supply chain management: review of best practices and conceptual framework. Development of management and entrepreneurship methods on transport. 2 (75), 38-64. DOI 10.31375/2226-1915-2021-2-38-64. 